\title{
Utilizaçào de glicose por bactérias heterotróficas no ecossistema lacustre da Amazônia Central
}

\author{
Hakumat Rai (")
}

\begin{abstract}
Resumo
Estuda-se a utilização da glicose por microrganismos em dois lagos amazônicos (Tupe e Janauari) durante um ano. As populaçöes bacterianas do lago Tupe säo aproximadamente 1000 vezes menores, e a do Janauari 100 vezes menores que as populações de bacterias de lagos de região temperada. A capacidade de mineralização por bactérias heterotrópicas é muito baixa e o tempo de "turnover" do substrato orgânico é muito prolongado.
\end{abstract}

\section{INTRODUÇÃO}

A substância orgânica, dissolvida na água doce, consiste de centenas de componentes diferentes, cada um presente em quantidades mínimas. É provável que as bactérias, constantemente, removam alguns dos componentes mais simples, que, por sua vez, são formados continuamente pela degradação de moléculas maiores. Por se verificar a importância de determinados componentes orgânicos para os organismos aquáticos é que se determina a taxa de sua formação e ingestão, mais que sua concentração absoluta em um dado tempo, pois, é potencialmente de maior importância. A substância orgânica solúvel representa uma fonte de energia para os microrganismos heterotróficos em ambiente aquático. Pela “absorção" bacteriana, energia química é introduzida na cadeia alimentar. Os processos de decomposição, em que participam microrganismos, dividem-se, do ponto de vista químico, em 2 categorias:

1. "Desagregação" hidrolítica dos complexos polímeros orgânicos, que constituem a maior parte dos corpos animais e vegetais, em compostos de baixo peso molecular:

2. "Desagregação" não hidrolítica das pequenas moléculas resultantes, geralmente acompanhada de consumo de oxigênio. Através deste último processo (mineralização) as moléculas orgânicas dos ambientes aquáticos são convertidas em compostos inorgânicos utilizados como nutrientes para plantas. Os processos de decomposição e mineralização estão apresentados diagramaticamente na figura 1.

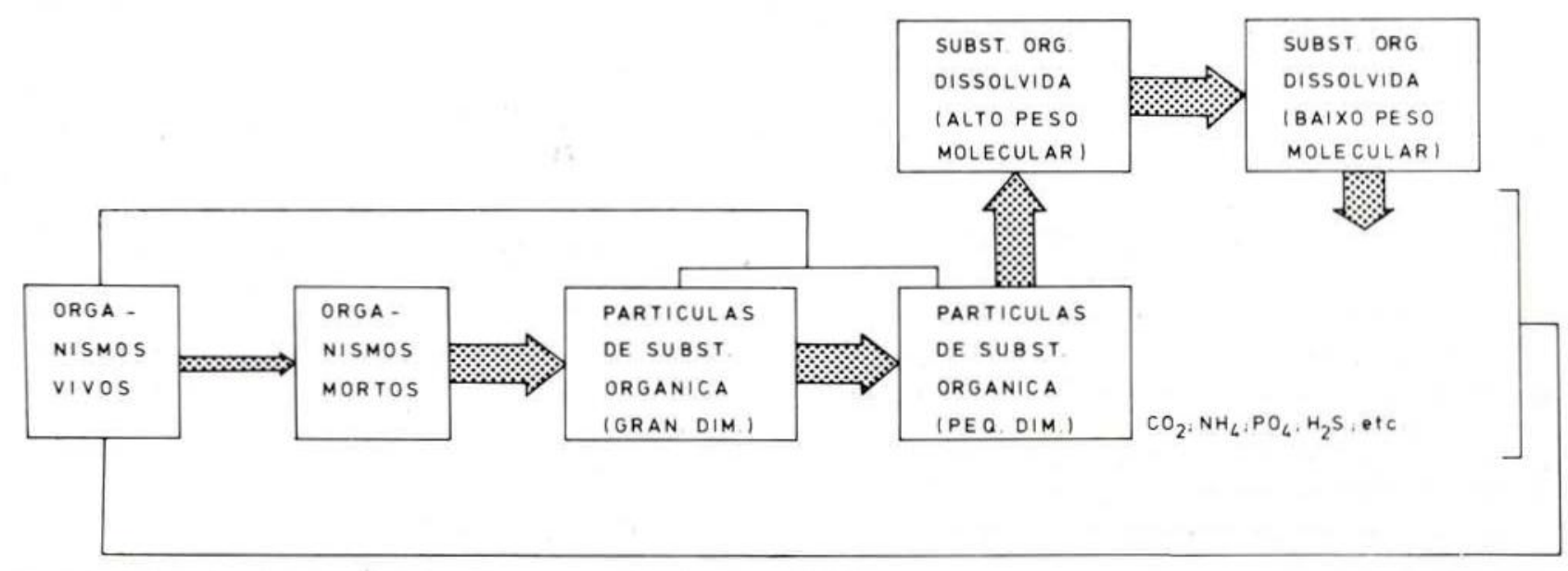

Fig. 1 - Sob a figura : Decomposição da matéria orgânica em ambiente aquático. Nos quadrinhos, da esquerda à direita, fila inferior: organismos vivos; organismos mortos; partículas de substâncias orgânicas; partículas de substância orgânica (particulas menores); fila superior : subst. orgânica dissolvida (peso molecular elevado); subst. org. dissolvida (peso molecular pequeno).

( $\left.{ }^{*}\right)$ - Max-Planck-Institut für Limnologie, Abt. Tropenökologie, Plön/H., Alemanha, $\epsilon$ Instituto Nacional de Pesqulsas da Amazônia, Manaus. 
MATERIAL E MÉTODOS

Coletaram-se todas as amostras no centro do lago (Tupé ou Janauari, próximos de Manaus), a intervalos de um metro, chegando aproximadamente ao fundo do mesmo. Coletaram-se as amostras num aparelho estéril que permite a coleta sem interferir na concentração de oxigênio. Este aparelho, mostrado na figura 2, foi desenhado e construído pelo autor, no Max Planck Institut für Limnologie, Plön, Alemanha Ocidental.

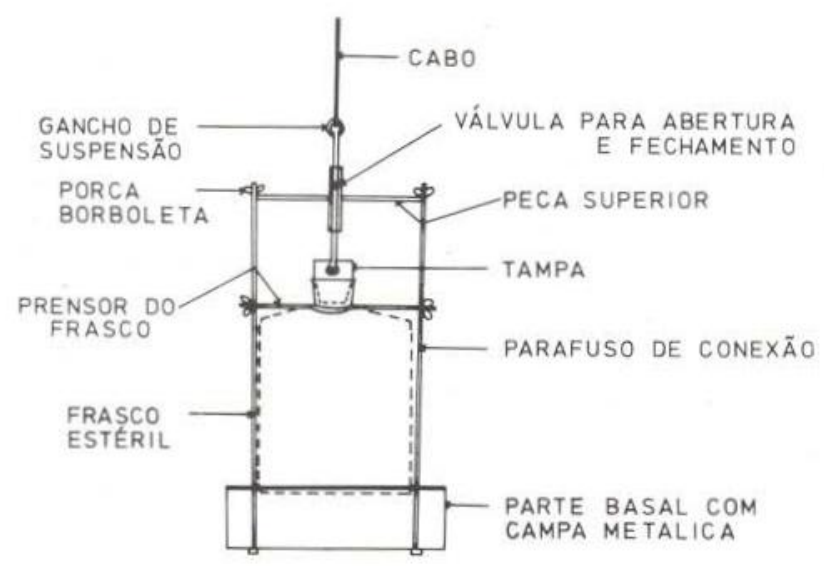

Fig. 2 - Sobre a figura : Desenho do aparelho de amostragem. A esquerda, de cima para baixo: gancho de suspensão, porca borboleta, prensor do frasco, frasco estéril. A direita, de cima para baixo: cabo, válvula para abertura ou fechamento, peça superior, tampa, parafuso de conexão, parte basal com chapa metálica.

Após a coleta, as amostras foram transportadas ao laboratório, e colocadas em incubadoras, com a temperatura equivalente à de cada profundidade do lago. Após um período curto para estabilizar a temperatura, as amostras foram colocadas num agitador magnético e depois filtradas em filtros Mf, de poros de $0,8 \mu \mathrm{m}$. A determinação do oxigênio dissolvido foi feita antes do começo e no término da experiência. O oxigênio permaneceu constante nos valores "in situ" durante todos os experimentos. Acréscimo de substrato ( $\mathrm{C}^{14}$ glucose) foi feito de acordo com o padrão descrito por Wright \& Hoibie (1966). Para os controles, os organismos foram mortos usando-se $0,15 \mathrm{ml}$ de formaldeído $(40 \%)$. Foram empre- gados nove frascos de amostras para cada profundidade. Glicose (UL) - $\mathrm{Cl}^{14}$ (Amersham Searle Corp) foi usada como substrato Esta foi diluída à radioatividade de $1 \mu \mathrm{Ci} / \mathrm{ml}$. O acréscimo usual foi de $25 \mu \mathrm{l}, 50 \mu \mathrm{l}, 100 \mu \mathrm{l}$ e $200 \mu \mathrm{l}$ em duplicata e $25 \mu \mathrm{l}$ acrescentados ao controle. As amostras e os controles foram incubados na temperatura "in situ", no escuro, durante 60 a 120 minutos, dependendo da atividade das populações. Após a incubação foi sustado o metabolismo por acréscimo de $0,15 \mathrm{ml}$ de formalina por amostra. Foram filtradas todas as amostras em Sartorius MF, de poro de $0.2 \mu \mathrm{m}$, num período de 10 horas. Os filtros foram secados sob lâmpada infravermelha e dessecados. O papel de filtro depois de seco foi dobrado e colocado num frasco de cintilação, acrescentando-se $15 \mathrm{ml}$ de fluido de cintilação contendo $4,0 \mathrm{~g}$ de $2,5 \mathrm{di}$ feniloxazole (PPO) e $50 \mathrm{ml}$ de 1,4-2 (5-feniloxazolil)-benzeno (POPOP) por $1000 \mathrm{ml}$ de tolueno. Todas as determinações da radioatividade foram feitas com um espectrômetro de cintilação líquida da Packard Instruments.

A eficiência da contagem fơi aferida pela padronização internacional com $\mathrm{C}^{14}$ - tolueno padronizado (Packard Instruments). Wolfe \& Schelske (1967) demonstraram a possibilidade do emprego deste método, que depois ficou confirmado por J. E. Hobbie (participação verbal).

O parâmetro cinético, associado com a remoção heterotrófica da glicose pelas bactérias aquáticas consiste no seguinte: $V_{\max }$, a velocidade teórica máxima de "uptake" em $\mu \mathrm{g}$ removida por litro por hora; $\mathrm{Kt}+\mathrm{Sn}$, um valor aproximado à concentração do substrato natural, em $\mu \mathrm{g}$ de glicose por litro; e Tt, o tempo de transformação em horas, necessário para que o substrato seja removido completamente da solução pela população natural presente na amostra. A fórmula proposta para a velocidade de "uptake" é a seguinte:

$$
\mathrm{V}=\left(\operatorname{cf}\left(\mathrm{S}_{\mathrm{n}}+\mathrm{A}\right) / \mathrm{C} \mu \mathrm{t}(1)\right.
$$

onde $\mathrm{V}$ é a velocidade de incorporaçăo $(\mathrm{mg} / \mathrm{l} / \mathrm{hr})$, c é a radioatividade dos organismos filtrados (CPM), $f$ é o fator isotópico de discriminação, $\mathrm{Sn}$ é a concentração natural do substrado $(\mathrm{mg} / \mathrm{l}), A$ é a concentração $(\mathrm{mg} / \mathrm{l})$ 
do substrato adicionado, C é a atividade (CPM) de $1.0 \mu \mathrm{Ci}$ do substrato no contador usado, $\mu$ é o número de $\mu \mathrm{Ci}$ adicionado e t é o tempo de incubação em horas. $O$ fator $f$ não foi considerado na maior parte do trabalho que se seguiu, por ser o seu valor desconhecido, embora considere-se que seja aproximadamente equivalente a uma unidade. Parsons \& Strickland (1962) desenvolveram uma equação semelhante à equação de Lineweaver-Burk, que poderia ser usada para determinar o valor de $\left(\mathrm{K}_{\mathrm{t}}+\mathrm{S}_{\mathrm{n}}\right)$ onde $\mathrm{K}_{\mathrm{t}}$ é uma constante de "uptake" análoga à constante de Michaelis, depois de determinar se o "uptake" relativo em várias concentrações de substrato adicionado. $S_{n}$, em geral não foi possivel medir em águas naturais, devido às limitaçōes dos métodos analíticos atuais. Os valores de $\left(K_{t}+S_{n}\right)$, no entanto, foram sempre inferiores a $20 \mu \mathrm{g}$ de $\mathrm{C} / \mathrm{I}$.

Dai acredita-se que, ao adicionar-se rotineiramente $250 \mu \mathrm{g} \mathrm{C} / \mathrm{I}$, qualquer efeito de $\mathrm{S}_{\mathrm{n}}$ na equação (1) poderia ser desprezado, e esta equação poderia ser usada para fazer-se comparações entre o potencial heterotrófico de diferentes águas.

Wright \& Hobbie (1965 e 1966) verificaram que o "uptake" de glicose e acetato, pelas populações naturais do lago Erkin, seguiu a equação cinética de Mechaelis-Menten somente em concentrações baixas. O "uptake" na amplitude de 0,5 a $5 \mathrm{mg}$ substrat/litro seguiu a cinética de primeira ordem. Por isso, Wright \& Hobbie duvidaram da validez das medidas de potencial heterotrófico relativo de Parsons \& Strickland (1962). Desenvolveram então uma equação para descrever a utilização do substrato, com base numa modificação da equação de Lineweaver-Burk:

$$
\mathrm{S} / \mathrm{V}=\mathrm{K}_{\mathrm{t}} / \mathrm{V}_{\max }+\mathrm{S} / \mathrm{V}_{\max }
$$

onde $\mathrm{S}$ é a concentração do substrato, $\mathrm{V}_{\mathrm{max}}$ a velocidade máxima de incorporação e $\mathrm{v}$ a velocidade de "uptake" (mg/l/hr) numa dada concentração de substrato. Em águas naturais, $\mathrm{S}_{\mathrm{n}}$ é desconhecido e, usando-se o conceito de Parsons \& Strickland (1962), o S da equação (2) torna-se $\left(S_{n}+A\right)$ como se segue:

$$
\left(S_{n}+A\right) / V=K_{t} / V_{\max }+\left(S_{n} A\right) / V_{\max }
$$

A equação (1) é reestruturada de forma que:

$$
\left(S_{\mathrm{n}}+\mathrm{A}\right) / \mathrm{v}=(\mathrm{C} \mu \mathrm{t}) / \mathrm{c}
$$

Substituindo-se a equação (4) na equação (3) e fazendo um rearranjo temos:

$$
(\mathrm{C} \mu \mathrm{t}) / \mathrm{c}=\left(\mathrm{K}_{\mathrm{t}}+\mathrm{S}_{\mathrm{n}}\right) / \mathrm{V}_{\max }+\mathrm{A} / \mathrm{V}_{\max }
$$

A partir desta equação, plotaram-se as medidas de incorporação em diferentes concentrações baixas de substrato adicionado, tendo $\mathrm{C} \mu \mathrm{t} / \mathrm{c}$ na ordenada e A (substrato adicionado) na abcissa. Portanto, o declive é $1 / \mathrm{V}_{\max }$ e a interseção sobre a abcissa é $-\left(K_{t}+S_{n}\right)$. A interseção na ordenada é $\mathrm{S}_{\mathrm{n}} / \mathrm{v}$ que é igual a duração do "turnover", Tt assumindo se uma produção e remoção constante do substrato. $\left(\mathrm{V}_{\mathrm{max}}\right)$ é a velocidade de "uptake" acima da qual um aumento nas concentrações do substrato deixam de ter efeito. No que se refere ao sistema microbial de transporte, $\mathrm{V}_{\max }$ é a velocidade de "uptake" atingida quando o mecanismo portador está satürado com substrato.

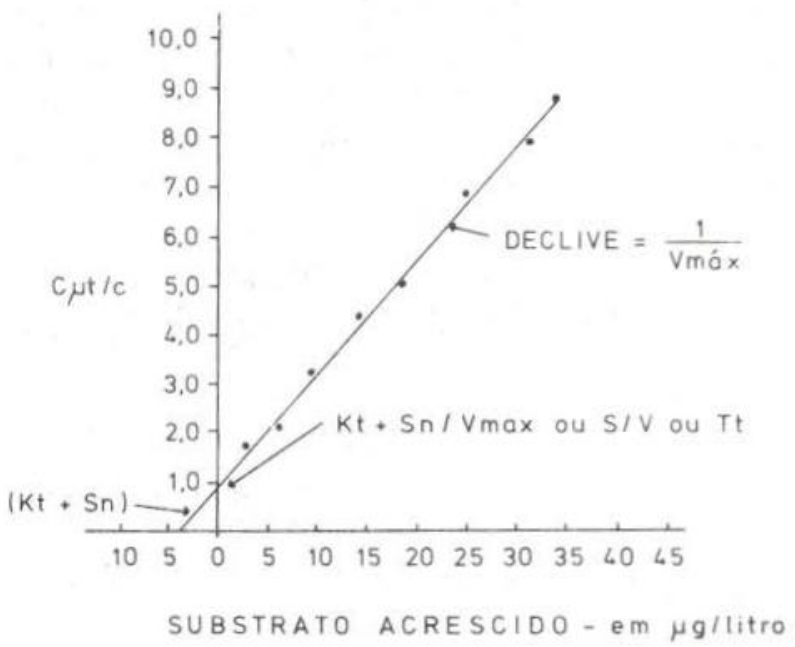

Fig. 3 - Sobre a figura: Substrato acrescido em ug/litro. Absorção de glicose em populaçōes naturais, ploteada de acordo com a equação $\mathrm{C}_{\mu} \mathrm{t} / \mathrm{c}=\mathrm{K}_{\mathrm{t}}+$ $\mathrm{S}_{\mathrm{n}} \mathrm{J} / \mathrm{V}_{\max }+\mathrm{A} / \mathrm{V}_{\max }$. A direita da figura: declive.

Correção para respiração foi similar àquela descrita por Hobbie \& Crawford (1969), exceto que, após a incubação, porções de amostras de $5,0 \mathrm{ml}$ (acréscimos de 25, 50, 100 e $200 \mu \mathrm{l})$ foram adicionados com seringa aos frascos vedados de respiraçäo (Kondes Glass 
Co.) que continham $0,5 \mathrm{ml}$ de $2.0 \mathrm{~N} \mathrm{H}_{2} \mathrm{SO}_{4}$. O $\mathrm{CO}_{2}$ desprendido foi capturado num pedaço de papel $(25 \times 51 \mathrm{~mm})$ cromatográfico Watman 40 dobrado e saturado de fenetilamina (Packard Instruments), na taça do frasco de respiração. Após 90 minutos, para assegurar a total captura do C0-14, o papel foi colocado num tubo de cintilação contendo $1.0 \mathrm{ml}$ de metanol. Foi adicionado então $15 \mathrm{ml}$ de fluído de cintilação contendo $4.0 \mathrm{~g} \mathrm{2,5}$ de difeniloxazole (PPO) e $50 \mathrm{mg}$ 1,4-2-(5-feniloxazolil)-benzene (POPOP) por $1000 \mathrm{ml}$ de toluene. O metanol foi armazenado a seco sobre $\mathrm{Na}_{2} \mathrm{SO}_{4}$ para evitar que ocorresse "quenching". Foi constatado que $80 \%$ da atividade de $\mathrm{Na}_{2} 14-\mathrm{CO}_{3}$, acrescida à câmara de respiração, foi recuperada pelo papel de filtro saturado de fenetilamina. Isto é comparável aos resultados obtidos por Hobbie \& Crawford (1969). Daí, a atividade do $14-\mathrm{CO}_{2}$ respirado (decarboxilado) foi calculado como se segue:

$$
r=r^{\prime} 1,25(36,08 \mathrm{ml} / 5,0 \mathrm{ml})
$$

onde $r^{\prime}$ é a radioatividade (cpm) na porção 1,25 é o fator de correção para recuperação de $80 \%$ de $\mathrm{CO}_{2}$ e $(36,08 \mathrm{ml} / 5,0 \mathrm{ml})$ corrigem o valor, digo, volume original da amostra de $36,08 \mathrm{ml}$.

A porcentagem de substrato adicionado respirado foi calculado pela seguinte equação:

$$
R=(r / c) 100
$$

onde $R$ representa a percentagem de substrato respirado (decarbocilado), $r$ é a radioatividade (cpm) em $\mathrm{CO}_{2}$-14 e c é a soma da radioatividade $(\mathrm{cpm})$ nas células e $\mathrm{CO}_{2}$.

Experiências preliminares demonstraram que isto era relativamente constante em qualquer experimento; por esta razão, calculou-se a média para os quatro valores de R. Esta média foi empregada para corrigir $\mathrm{c}$ na equação (5) para a respiração, como segue:

$$
c=(100 /(100-R) X
$$

onde $\mathrm{R}$ é o porcentual médio respirado (decarbocilado) e $\mathrm{X}$ é a atividade das células.
RESULTADOS DE EXPERIÊNCIAS DE "UPTAKE" DE GLICOSE

Os resultados, apresentados nas figuras 4,5 e 6, são derivados da regressão linear da equação:

$$
(\mathrm{C} \mu \mathrm{t}) / \mathrm{c}=\left(\mathrm{K}_{\mathrm{t}}+\mathrm{S}_{\mathrm{n}}\right) / \mathrm{V}_{\max }+\mathrm{A} / \mathrm{V}_{\max }
$$

Mais que $95 \%$ das experiências resultaram $\mathrm{cm}$ regressões lineares de quadrados mínimos com coeficientes de determinação de 0,95 , ou mais.

O tempo de "turnover" da g'icose (fig. 4) foi diretamente proporcional às Hutuações do nivel da água. Este parâmetro flutuou grandemente durante o período do estudo. O tempo de "turnover" foi muito alto durante o período de estudo. As variaçōes médias mensais de "turnover" de toda a coluna de água estiveram entre 120 e 36.48 horas para o lago

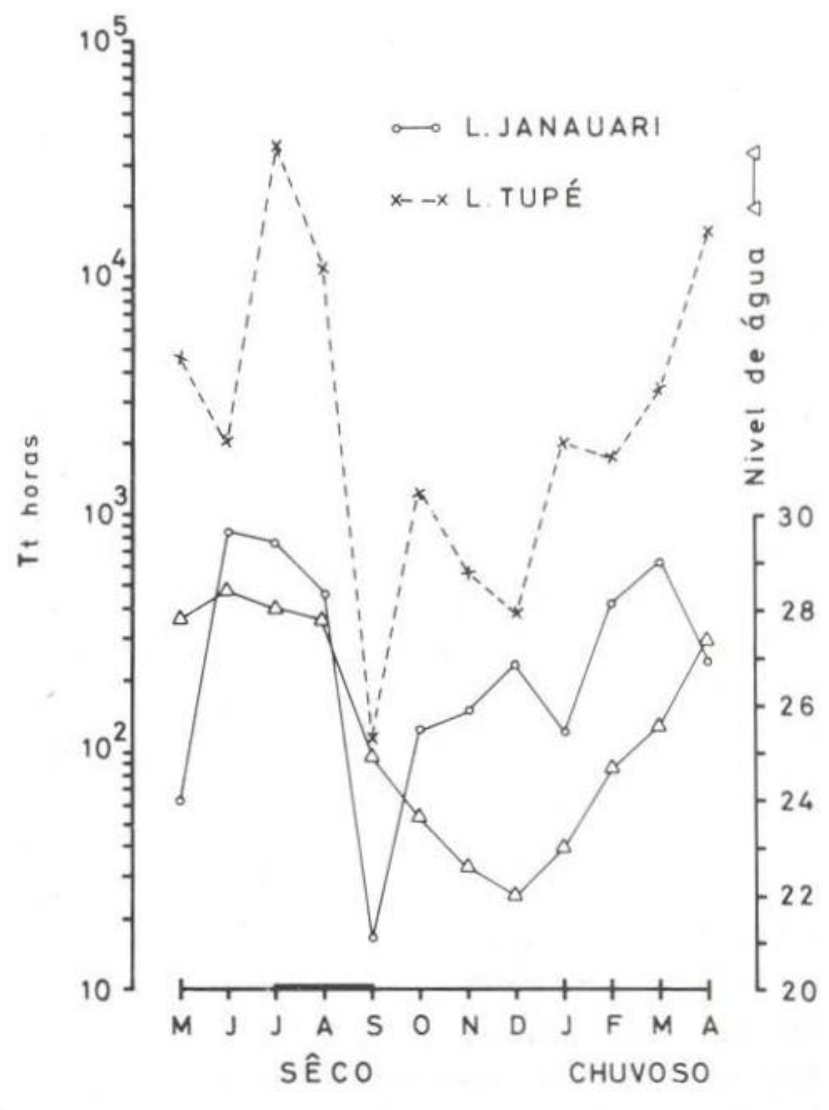

Fig. 4 - Sob a figura : Mudanças sazonais no "turnover, formação da glicose, nos lagos Tupé e Janauari, Amazônia. Ao lado da figura : tempo de "turnover" em horas. 
Tupé e oscilaram entre 17 e 1.350 horas para o lago Janauari. Ocorreu um grande acréscimo ao tempo de transformação concomitante do aumento do nível de água em ambos os lagos.

A velocidade máxima $\left(\mathrm{V}_{\max }\right)$ de "uptake" tendeu a aumentar nas fases de baixo nivel da água e diminuir a um mínimo nas fases do nivel mais alto (figura 5). No caso do lago Tupé, revelaram-se dois picos. O primeiro ocorreu em setembro e o segundo, através da maior parte de novembro e de dezembro e. para o lago Janauari, igualmente foram verificados dois picos, mas, o primeiro estendeu-se de outubro a novembro e o segundo, o pico muito alto, no mês de janeiro, quando a velocidade máxima foi de $51,9 \mu \mathrm{g} / 1 / \mathrm{h}$.

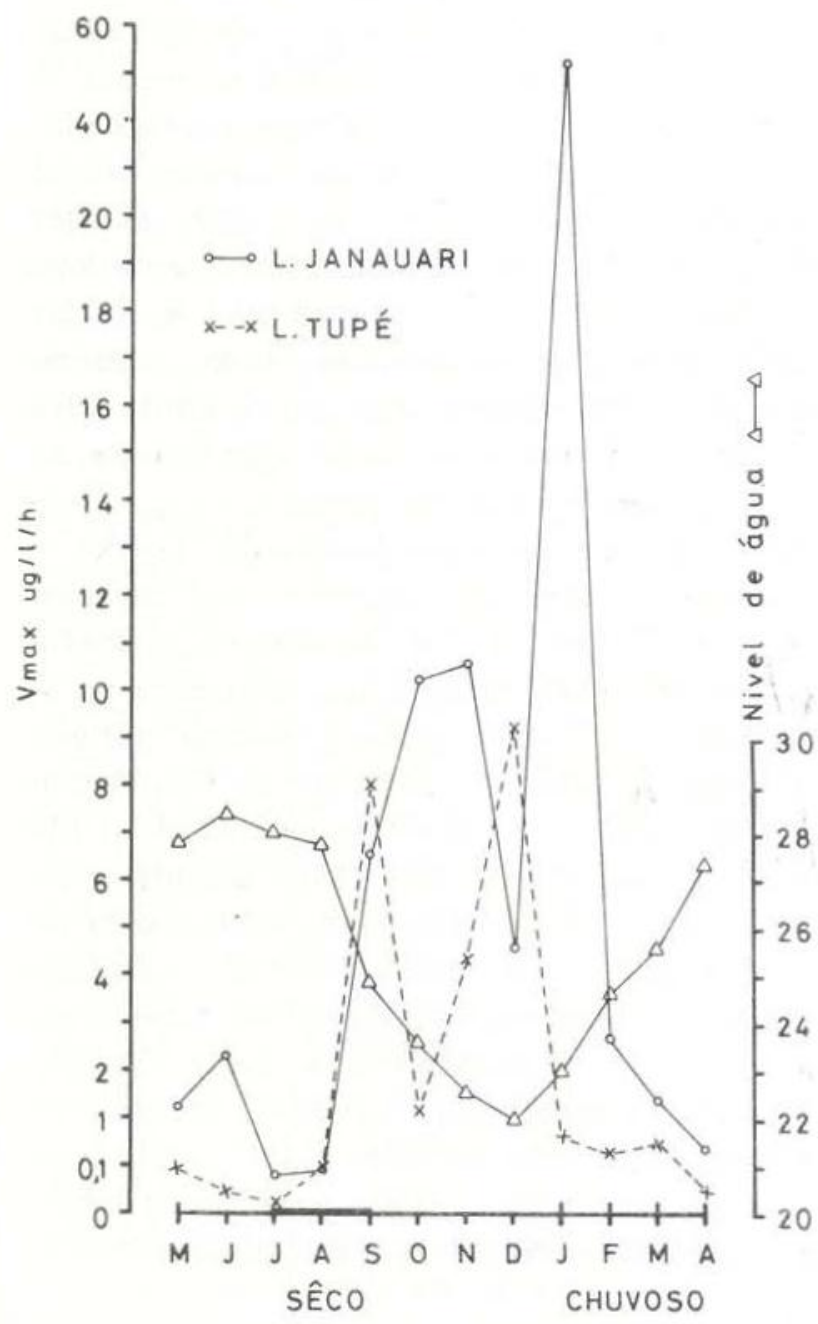

Fig. $5 \geq$ Sob a figura: Mudanças sazonais da velocidade máxima de "uptake" de glicose nos lâgos Tupé e Janauari, Manaus (Amazônia).
Os valores de $(\mathrm{Kt}+\mathrm{Sn})$ variaram amplamente, durante o período do estudo, em ambos os lagos (figura 6). Os valores tenderam a ser mais baixos durante o período de alto nível da água, e mais altos no período de baixo nivel da água. Em média, os valores para $(\mathrm{Kt}+\mathrm{Sn})$ no lago Tupé variaram entre $270 \mathrm{e}$ $1560 \mu \mathrm{g} / 1$ durante o período de estudo e, no lago Janauari, entre 135 e $1673 \mu \mathrm{g} / 1$.

\section{APROVEITAMENTO DA GLICOSE}

Os resultados da absorção de glicose revelaram que $V_{m_{a x}}$ (fig. 5) foi mantida pelas populaçōes naturais num mínimo praticamente constante durante a elevação do nivel da água. A velocidade máxima e $\left(\mathrm{K}_{\mathrm{t}}+\mathrm{S}_{\mathrm{n}}\right)$ foram diretamente proporcionais, pois, ambos aumentam e diminuem na mesma maneira, a fim de que o tempo de "turnover" permaneça constante. O sistema, por esta razão, pareceu operar de tal maneira a impedir a acumulação de glicose. Os resultados deste estudo demonstraram que $T_{1}$ não permaneceu constante. Os resultados, apresentados por Wetzel (1969), mostram a mesma tendência.

Porém, Allen (1969) e Hobbie (1969) não observaram esta tendência. A atividade da população heterotrófica pode ser indicada pela magnitude de $\mathrm{V}_{\max }$ (Hobbie, 1967 e Wright \& Hobbie, 1966). Se isto for admitido, então a atividade medida da glicose foi mais alta durante o decréscimo do nível da água, ou quando este está baixo.

Os grandes aumentos na duração da transformação da glicose durante a fase de nível alto da água foram significantemente diferentes dos valores da fase de baixo nivel da água, embora o $V_{\max }$ permanecesse quase inalterado e $\left(K_{t}+S_{n}\right)$ não aumentasse em grau apreciavel durante o período de alto nivel da água. $\mathrm{O}$ aumento do tempo da transformação ocorreu durante o aumento do nível da água. Esta mudança provavelmente deveu-se às populações trazidas ao lago a partir de seus locais de origem, que talvez não fosse de origem aquática. $V_{\max }$ parece ser alta, quando a população de bactérias vivas for numerosa e vi- 
ce-versa. Isto indica que a concentração da comunidade de bactérias vivas é responsável pelo "uptake" da glicose.

Durante o alto nível da água, os valores de $\left(K_{t}+S_{n}\right)$ e $V_{\max }$ são baixos, enquanto os valores de $T t$ e número de bactérias são altos (trábalho não publicado, Rai 1976). Enquanto que, em baixo nível de água, os valores de $\left(K_{t}+S_{n}\right)$ e $V_{\max }$ são altos e os valores Tt e o número de bactérias são baixos.

Os resultados desta pesquisa mostram que comunidades químio-organotróficas respondem com muita rapidez às mudanças do nível da água e da concentração do substrato. Durante a fase de aumento do nível da água, $V_{\max }$ foi muito baixa em ambos os lagos. Isto significa que a afinidade com o substrato foi o mais baixo neste período do ano. No período da diminuição do nível da água, $\mathrm{V}_{\max }$ foi mais alto em ambos os lagos, indicando, que, neste período, a afinidade com o substrato foi mais alta. Comparando-se medições em meios aquáticos de natureza trófica muito diferente, as taxas de "uptake" de glicose parecem ser

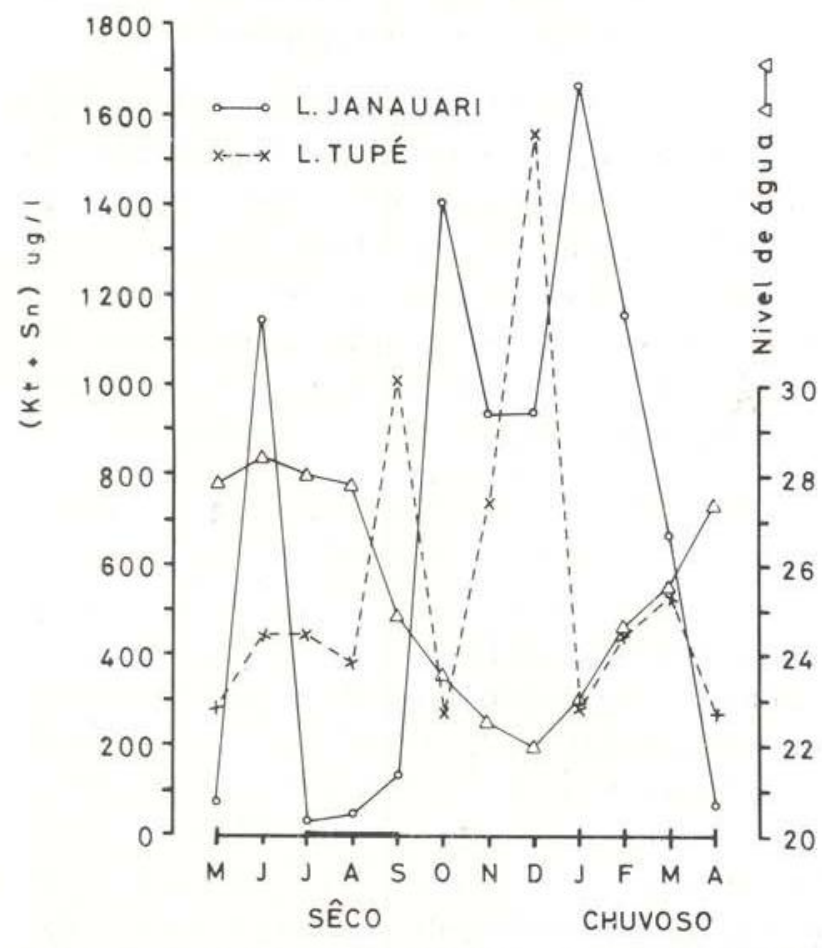

Fig. 6-Mudanças sasonais na concentração do substrato natural e nivel de água, nos lagos Tupé e Januari, Manaus (Amazônia). Ao lado da figura: nível da água em $\mathrm{m}$. relacionadas com o estado trófico. Quanto maior a produtividade da água, tanto mais alto será o $\mathrm{V}_{\mathrm{max}}$. Assim, isto indica que os lagos de água branca e mista (dados não publicados) são mais produtivos do que lagos de água negra da região amazônica.

$\mathrm{O}$ aumento no número total de bactérias durante o nível alto das águas não foi relacionado ao aumento de $\mathrm{V}_{\max }$ para o substrato estudado. Isto talvez se deva ao fato de que as bactérias vivas eram transportadas para os lagos durante as enchentes, a partir da área de recebimento dos lagos. Evidentemente, estas bactérias não têm um papel muito importante para o "uptake" da glicose. Istc significa que as modificações quantitativas e qualitativas nas populações bacterianas podem alterar o $\mathrm{V}_{\max }$. Foi registrada a exceção desta regra, na estação seca, durante os meses de setembro, novembro e dezembro, quando o aumento de bactérias vivas podia estar relacionado aos aumentos de $V_{\max }$ para glicose. As suposições de pesquisadores anteriores (Hobbie, 1967, Allen, 1969, Wright \& Hobbie, 1966) parecem confirmar-se pelo presente trabalho. No entanto, Morgan \& Kalff (1972) encontraram uma correlação significativa entre o número total de bactérias e o $\mathrm{V}_{\max }$. Ademais, com um grau aumentado de "uptake" e elevado número de bactérias, um processo ativo de degradação foi, geralmente, encontrado em setembro, novembro e dezembro no lago Tupé e, durante quase o mesmo período, no lago Janauari. O aumento no fitoplancton (como indicado pelos dados de clorofila) (dados não publicados, Rai, 1976) durante o período de estudo, foi associado ao aumento em $\mathrm{V}_{\max }$ e $\left(K_{t}+S_{n}\right)$ para o substrato estudado. Portanto, o aumento de $\left(K_{t}+S_{n}\right)$ sugere que as algas, no período de nível baixo da água, estavam acompanhadas por uma liberação de glicose, pois, não há razão para supor-se ter havido aumento de $\mathrm{K}_{\mathrm{t}}$. Este padrão foi também descrito para o lago Erken, por Hobbie (1967).

\section{CONCLUSÕES}

1. Populações naturais tendem a impedir a acumulação de glicose durante o período de janeiro a agosto, isto é, o tempo de "tur- 
nover" do substrato ( $T$ t) não permanece constante ao redor de um mínimo, enquanto que a velocidade máxima $\left(\mathrm{V}_{\mathrm{m}_{\mathrm{ax}} \mathrm{x}}\right)$, a soma da constante de transporte $\left(K_{t}+S_{n}\right)$ e a concentraçăo do substrato variam notavelmente em ambos os lagos.

2. Durante o período de nível elevado de água, os valores de $\mathrm{V}_{\max }$ não tenderam a aumentar com o número total de bactérias. Isto sugere que tenham havido mudanças qualitativas, assim como quantitativas na população de bactérias.

3. A concentração de bactérias vivas (contagem em placas) foi inversamente relacionada ao $\mathrm{V}_{\max }$.

4. $V_{\max }$ para o lago Tupé foi geralmente inferior do que para o lago Janauari.

5. Tt aumentou, enquanto $\mathrm{V}_{\max }$ e $\left(\mathrm{K}_{\mathrm{t}}+\right.$ $\mathrm{S}_{\mathrm{n}}$ ) diminuiram durante o período de nivel elevado da água. Isto provavelmente refletiu a diminuição geral na atividade de toda comunidade biológica durante o período de alto nivel da água. Estes achados são semelhantes àqueles para os lagos temperados durante o inverno.

6. Como já assinalado antericrmente, por pesquisadores da água da região amazô. nica, as bactérias estavam procedendo à mineralização da matéria orgânica tão rapidamente quanto a substância orgânica era produzida. Isto significa que, na verdade, deveria haver deficiências. Ou alternativamente, uma situação em que o "input" no acervo orgânico (bactérias) é igual ao "output"; mostraria também mudanças de zero ( $\mathrm{Tt}$ ) tempo de "turnover". Este fenômeno peculiar foi observado por Allen (1969) em duas amostras em que foram detectados valores positivos de $\left(\mathrm{K}_{\mathrm{t}}+\mathrm{S}_{\mathrm{n}}\right)$. A taxa mais elevada de "turnover" para glicose, como demonstrado nos casos de lago Janauari e lago Tupé especialmente durante o período de nível alto da água $\mathrm{e}$, em geral, durante todo ano, pareceria ocorrer devido à presença de populações bacterianas muito pequenas. O trabalho de Allen (1969) mostrou em suas experiências a mesma tendência. Populações bacterianas do lago Tupé são aproximadamente 1000 vezes menores. e as do lago Janauari, aproximadamente 100 vezes menores do que as populaçôes habituais de bactérias de lagos de região temperada

7. Este trabalho, como um todo, indica que em águas da região amazônica, em geral, a capacidade de mineralização por bactérias heterotróficas é muito baixa e o tempo de "turnover" do substrato orgânico é muito prolongado.

\section{Agradecimentos}

Este trabalho foi patrocinado pelo Prof H. Sioli, Diretor do Max-Planck-Institut für Limnologie, Abteilung Tropenökologie, Plön, Alemanha Ocidental e Prof. W. E. Kerr, Diretor do Instituto Nacional de Pesquisas da Amazônia, Manaus, Brasil. O trabalho foi idealizado e executado num espírito de cooperação entre o Max-Planck Institut für Limnologie e o Instituto Nacional de Pesquisas da Amazônia.

Agradeço à Profa. Miriam Becker e D. Luise Korner pela tradução desta publicação.

\section{SUMMARY}

A year long study on the utilization of glycose by the microorganisms of two Amazonian lakes (Tupé and Janauari) were studied. The bacterial populations of lake Tupé is approximately 1000 times smaller, and that of lake Janauari 100 times smaller than those of lakes from temperate regions. The mineralization capacity by heterotrophic bacteria is very low, and the organic substrate turnover time is very long.

\section{BIBLIOGRAFIA CITADA}

Allen, H. L,

1969 - Chemo-Organotrophic utilization of dissolved organic compounds by Planktic Algae and Bacteria in a Pond. International Revue Gesamt Hydrobiologie, $54: 1-33$.

НоввIе, J. E.

1967 - Glucose and acetate in Freshwater: Concentrations and Turnover Rates. In: Golterman \& Clymo eds. - Chemical enronment in the Aquatic. Habitat. Proceedings of an 1; B. P. Symposium held in Amsterdam and Nieuversluis, October 10-16, 1966.

Hobrie, J. E. \& Crawford, C. C.

1969 - Respiration corections for Bacterial Uptake of Dissolved Organic compunds in Natural Waters. Limnology and Oceanog., 14: 528-532. 
MORGAN, K. E. \& KALFF, J.

1972 - Bacterial dynamics in two higharctic lakes Freshwat. Biol., 2 : 217-228.

PARSONS, T. R. \& STRICKLAND, I. D. H.

1962 - On the productioo of particulate organic Carbon by Heterotrophic Processes in sea water. Deep Sea Research, $8:$ 211-222.

Wetzel, R. G.

1969 - Dissolved organic compounds and their Utilization in two Marl Lakes. Hidrological Kozlony, 47 : 298-303.
Wolfe, D. A. \& SchelsKe, C. L.

1967 - Liquid scintillation and Geiger counting efficiencies for Carbon-14 Incorporated by Marine Phytoplankton in Productivity measurements. Journal du Consiel International Pour L'Exploration de la mer, 31: 31-37.

WRIGHT, R. T. \& НовBIE, J. E.

1965 - The Uptake of Organic solutes in Lake Water. Limnology and Oceanography, 10: 22-28.

1966 - Use of glucose and acetate by Bacteria and Algae in Aquatic ecosystems. Ecology, 47: 447-464.

(Aceito para publicação em 06/01/78) 